\title{
Engineering Discourse in the Structure of the ESP Training at Southern Federal University
}

\author{
Ellina Sidelnik $^{1, *}$, Olga Melnik $^{2}$, Lyudmila Burenko $^{1}$ \\ ${ }^{1}$ Department of Foreign Languages, Engineering Technological Academy of Southern Federal University, Russia \\ ${ }^{2}$ Department of Linguistic, Engineering Technological Academy of Southern Federal University, Russia
}

Copyright $(2016$ by authors, all rights reserved. Authors agree that this article remains permanently open access under the terms of the Creative Commons Attribution License 4.0 International License

\begin{abstract}
This paper discusses the essentials of engineering discourse in the structure of the ESP training at Southern Federal University (SFU) (Taganrog, Russia). The purpose of this paper is to justify critical rethinking of existing programs of technical students training in foreign languages at SFU taking into account the increasing role of engineering discourse in the professional socialization of future engineers and to enable them to integrate into the international professional community. The undertaken analysis strives to find the way to change the teaching practice of ESP. There are two levels of foreign language acquisition at SFU. At the first level students study any foreign language in a context of the general language. And at the second level they get conceptual knowledge to acquire scientific and professional terminology of any foreign language in order to become a professional language personality. To support these objectives a series of text books on ESP courses (Computer Engineering, Radio Engineering, Electronic Engineering etc.) have been developed at the foreign languages department SFU. The textbook "Computer Engineering" has been considered in details in this article. The authors have suggested directions in which the discourses of engineering education and practice need to change so that the engineering profession can achieve the goals stated in its professional codes.
\end{abstract}

Keywords Engineering Discourse, ESP Training, Language Professional Socialization, Foreign Language Acquisition, Professional Language Personality, ESP Text Books

\section{Introduction}

In Russia, the system of higher education is traditionally subdivided into three major spheres:

- natural-scientific,

- engineering,

- social-humanitarian.
Every sphere is taught at universities of different types and is implemented in appropriate discourses. For a long time the professional discourse was realized through the texts and was reduced to mastering different kinds of translation and learning professional vocabulary. In view of the development of international business contacts, the establishing numerous joined ventures and working in close cooperation with foreign specialists the country needs engineers who speak foreign languages on the level sufficient for dialogue cooperation. Cross-cultural communication determined by the development of information field is viewed by many researchers as the priority direction of linguistic education on modern stage. According to I.L. Pluzhnik [Pluzhnik, 14] in professional cross-cultural communication, we differentiate the triad:

- lingvo-sociocultural competence (the usage of linguistic means in accordance to the cultural norms of the language in the professional sphere of activity);

- discursive competence (professional conception of interactive behavior in business situations of different language community);

- $\quad$ thesaurus competence (the knowledge of semantic and the connection between the words and concepts).

In spite of substantial experience accumulated in the foreign language teaching in Russia (O. Safronenko, 2006, L. Salnaya, 2007, O. Almabekova, 2011) we could observe insufficient attention to the integration of theory and practice of English for Specific Purposes (ESP) and professional communication. The purpose of this paper is to justify critical rethinking of existing programs of technical students training in foreign languages at Southern Federal University (SFU) taking into account the increasing role of engineering discourse in the professional socialization of future engineers.

\section{The Notion of Discourse}

We assume discourse as a basis of discourse competence. Discourse was originated from the Latin word discursus 
meaning "conversation", "talk" but at present it is more often interpreted in many different languages as "speech", "linguistic performance", "method of talking".

The term "discourse" has been changing its meaning during some decades. In the $60-70 \mathrm{~s}$, it was referred to as a connected sequence of sentences or speech acts, in other words, it correlated with the notion "text". From the position of contemporary approaches discourse is a complex communicative phenomenon which involves apart from the text some extralinguistic factors (the knowledge of the world, opinions, guidelines, the aims of the addressee) that are important for the comprehension of the text [Karaulov, Petrov 2015; 8].

The term "discourse" gradually penetrates into the foreign languages learning theory where it is starting to play a crucial role as for a long period of time the practice and theory of language teaching has been text-oriented.

There are several advantages of $a$ text as a didactic material. Firstly, it is an authentic sample of speech which is holistic and complete in form and contents. Secondly, it represents some topic inducing the communication and finally it contains some lexical and grammatical material [Yeluhina 2002, 9].

However, a text does not meet all the requirements of foreign language teaching today as the expression and achievement of partners' intercourse aims are significant in the act of communication but not just the topic of the text, not just its language forms.

In this connection, it is considered expedient to correlate the notions "discourse" and "text". Defining the notions, the scientists remark that text as a language material does not always correspond to speech or discourse. Aiming at differentiating text and discourse we should emphasize that discourse represents the language both as a process with regard to extra linguistic factors in the act of communication and as a result in the form of a text.

According to N.D. Arutyunova, discourse is a text supplemented with events and facts [Arutyunova 1990, 136-137].

M.L. Makarov defines discourse as a text and situation joined in one structure. The investigator distinguishes discourse and text regarding their opposing criteria. Discourse is dynamic and actual whereas text is static, structured, simulated [Makarov 2003, p.4].

Teun A. Van Dijk, who is considered to be a pioneer of the theory of text, the theory of speech acts and discourse analysis writes: "I advocate a broad multidisciplinary approach to discourse, which integrates a detailed and explicit study of structures of text and talk with an analysis of their social and cognitive contexts as a basis for problem-oriented critical discourse analysis. In such an approach, the study of relevant knowledge, ideologies and other socially shared beliefs is crucial in describing many of the properties and social functions of discourse". [2 Teun A. Van Dijk, p.161]. In his work "From text grammar to critical discourse analysis. Academic autobiography." we find: “... discourses are obviously not coherent in the abstract, but coherent

for-discourse-participants-in-some-communicative-situation" [1Teun A. Van Dijk, p.4] and the investigator also points out that "pragmatic and cognitive parameters need to be added to this kind of definition." [1Teun A. Van Dijk, p.4].

Therefore, after T.A. Van Dijk, comparing the notions discourse and text we regard discourse as a communicative event happening with participants in the process of communicative act in some temporal, spatial and other aspects. The act can be in oral or written form, verbal or nonverbal. Text can be defined as a communicative unit, which consists of a certain sequence of sentences, words. It is constructed according to the rules of a given language and system of signs and it forms a message [the Linguistic encyclopedic dictionary. - M.: Sov. Encyclop.. 136-137].

\section{Engineering as a Discursive Complex}

L.V. Stupnikova [2010: 3] notes that while teaching ESP one cannot content oneself with using the text because it does not provide possibility to demonstrate to students the features of speech utterances, which can become apparent only in the dynamics of communication.

The foreign language lecturers often have to work with the students having low level of language competence. The differences in demands at school and at the higher education institutions are stipulated by the contradictions between the language training at school and at university. State Educational Standard at university is based on the competence approach, whereas such standard for schools is based on the systemic-functional approach.

In this connection, it seems to be appropriate that the first attempts to solve the problem of teaching communicative skills in Russia appeared within the frame of the foreign language course. This goal is excellently illustrated by the name of the course "English for Specific Purposes". Nevertheless, there are two reasons that do not allow to speak seriously about the forming of professional communicative competence:

- general poor training in foreign language at school (according to the Placement Test the proficiency of $75 \%$ of the first year students in 2015 at SFU correspond to the Elementary level);

- deficient amount of hours - according to the State Educational Plan of the Russian Federation only 340 hours is allocated to ESP).

Consequently, the professionally oriented training of the foreign language in the technical institution demands a new approach to the content selection. It should be oriented to the latest achievements in the spheres of human activity that are closely connected with students' professional interests and give them possibility of professional growth.

Modern psychology operates with such terms as "hard skills" and "soft skills". Competitive specialist should 
possess not only technical knowledge (hard skills), but also a set of humanitarian qualities and competences such as ability to work in a multidisciplinary team, possession of effective argumentation and communicative competence in general, understanding professional and ethical responsibility while taking engineering decisions, capability for analysis and criticism of the engineering decisions that were already made, the skill of people management and realizing the necessity of life-long learning (soft skills).

According to C. Tenopir and D. King [149-161] not less than $50 \%$ of working time the engineer spends on different kinds of professional communication: business discussion and taking part in meetings; reading articles, reports, emails, consulting activity, professional presentations and preparing claims for engineering projects, technical documentation, preparing books and articles, developing programs and software applications.

In the paper reviewing engineering education in Australia S. Johnston, A. Lee, H. McGregor [1996; 4] enumerate the kinds of discourses that are closely interrelated with the engineering discourse:

- management, including the management of engineering activity. In so far as this requires understanding of technical as well as personnel and financial issues, it is recognizable as essentially engineering activity;

- business, including supporting innovation in systems, processes, and products as well as economics and wealth creation;

- industrial design, including aesthetic and ergonomic issues. The needs of the users will to a large extent determine the appropriateness of the design of the system or product;

- sociology, including locating engineering in its social and cultural contexts;

- politics and development, including equity issues at national and international levels;

- $\quad$ philosophy and ethics (and etiquette);

- environmental studies (itself a discursive complex).

The argument here is not that one discourse should supplant another, for example, that engineering science should be replaced by business in defining what is appropriate or necessary for engineering activity. The task of the lecturer is to combine different kinds of discourses in the way so that they become mutually supplemented.

\section{Recontextualizing Engineering Education}

ESP training at the Southern Federal University focuses at the professional language socialization and the development of professional culture. These should help our students to become more competitive and easily adapt at the global labour market.

Socialization of any personality happens in the course of his/her integration into the society, by assimilating its social norms and values. A language (especially a foreign one) is one of the most productive ways of this integration. Edward Sepir [2002] in his classical works noted that language is the great lever of socialization, perhaps the greatest of all existing, language is a symbolical key to behavior. Therefore, language education can be a basis of the personality's self-development and his/her intellectual growth, an indicator of readiness for productive activity in society.

Currently scientists consider professional socialization as social and professional interaction, which is carried out at three levels: institutional, group and personal. [Vaysburg, 2009].

Professional and labor socialization is the professional development of the person based on the development of his or her professional qualities, which starts with early labor education and proceeds throughout all his/her life in interaction with the environment. Thus, the personality acquire social norms and cultural values and develops professionally in this society. [Krasnoperova, 2008].

Language verbal communication can be considered as the basis of professional socialization. Communicative competence gives any person a chance to develop most fruitfully in professional and social fields. Abilities to carry on dialogue, to achieve success in communication process are important components of professional qualities in various fields of activity. The modem expert has to be guided freely in quickly changing information space, possess ability to apply language purposefully and effectively, to be communicative and competent.

In Russian system of higher education, it is possible to allocate two levels of language socialization [Sidelnik, 2010: 123-127]. The first level is devoted to mastering language in the context of the general language. The second level is dedicated to conceptual knowledge (mastering words, terminological system, the category device, professional aspects of language in a context of scientific and narrowly professional language preparation) and directed at acquisition of professional language and professional communicative competence.

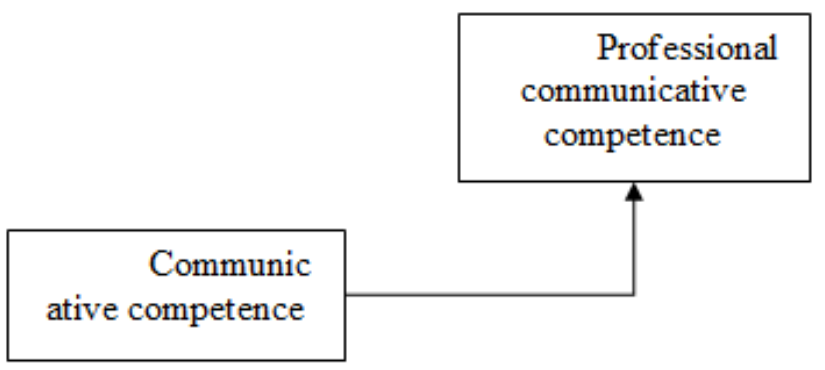

Figure 1. The structure of language socialization of engineering students.

The target of the first stage of language socialization in the higher education system we see not only in assimilation of a verbal code of any foreign language and ability to use it in practice, but also in formation «world pictures» inherent to a native speaker as a representative of a certain society and in formation of the valid and positive attitude to the culture of 
the countries of the studied language.

Language socialization at this stage assumes assimilation of trained values, standards of behavior, installations, peculiarities of the certain society, which cannot be understood and apprehended out of a language situation and speech.

The aim of the second level of language socialization, which as a rule takes place for example SFU during the $3 \mathrm{~d}$ and 4th years, is to form the professional language personality.

Language professional socialization is carried out by acquisition of professional language and communicative competence. The vernacular influencing consciousness and forming professional thinking is means of orientation in professional activity, helps to adapt to new conditions and acts as the agent of socialization.

Professional socialization means assimilation and reproduction not only of professional culture, (professional knowledge and abilities), but also includes a set of standards of behavior and relationship, and systems of the values. Professional socialization is closely connected with communicative activity; therefore, we can speak about «professional and communicative socialization».

We consider "professional and communicative socialization" as "... pedagogically organized form of the subject - subject interaction of the personality and the surrounding educational environment, that assumes active participation of a future expert in the acquiring of the human relations culture, in mastering a certain social and professional role, knowledge and communicative abilities necessary for his/her successful sociocultural integration, which results in the certain professional identity of the personality" [Shmakova, 2009: 14]. Successful realization of this process directly depends both on level of proficiency in a vernacular, and on degree of professional culture formation.

To realize targets facing us, that is development of the professional language identity of future experts and global competence at the Foreign Languages department of SFU in the city of Taganrog we study discourse with reference to engineering professions. The staff of the Foreign Languages department has developed a new educational and methodical complex ESP that is aimed at the professional focused business communication with a dominant of informal conversation training.

Within the framework of this ESP course, a series of textbooks such as Computer Engineering, Secure IT, Electronic Engineering, Radio Engineering, Land Surveying, Tourism and Service etc. was created, to develop and improve foreign-language communicative professional competence of students determined by program documents.

Let us consider more detailed the textbook "Computer Engineering". This textbook has been written taking into account the state program of training in foreign languages for engineering students for the specialties "Informatics and Computer Facilities" 230100 (552800) and "Automation and management" 220200 (550200). Authentic text material of thematic units and the developed system of exercises are professionally focused. The complexity level of the text material presented in units is adapted to students, who have gained the necessary linguistic competence having successfully done the basic course "Foreign language". In SFedU this level is equivalent to the first and second years of study at the bachelor degree.

The textbook "Computer Engineering" consists of 10 Units discussion the following issues: "Computer \& Computing", "Software", "Portable computers", "Programming languages", "Computer networking", "Computer graphics", "Multimedia", "Telecommunications", "Virtual reality", "Computer security".

Each Unit is devoted to the certain professional theme. The structure of the section allows students to facilitate language difficulties, speech and psychological problems in the course of assimilation of a training material. It is easy to be guided in the structure and context of the textbook and exercises.

The core of each unit is authentic text material. Pre-reading exercises aimed to facilitate difficulties during the work with the text are the following:

- $\quad$ phonetic (match the word with its transcription, etc.);

- lexical (match a word with its definition, etc.);

- collocational (to make phrases, etc.);

- grammatical.

After-reading exercises are aimed at fixing and activating of the studied language material.

Texts and the system of exercises presented in this textbook can be used for both group and independent work of students in the classroom under the teacher's supervision, and out-of-class work. The authors pay significant attention to arranging role-playing games, debates, game competitions, round table discussions, projects, presentations and other forms of professional problem discussions, because these activities help to simulate situations of the natural language professionally focused communication.

Number of the following tasks: Writing, Get Real, Speaking are targeted not only to improve intensively all types of students' speech activity, but also to develop creative thinking and students' individual approach to considering issues presented in the unit.

It would be desirable to dwell more upon the section Get Real. In this section, there are references to the Internet sites, which will help students to use creatively additional material getting ready with Writing and Speaking tasks.

\section{Recommendation}

Using IT, computers and Internet encourages students' activity and improves their professional competence, widen their scientific interests, develops their foreign language professional competence and enhances their motivation to study ESP.

Development of a vernacular in the system of higher 
education, gives students a chance further to carry out successfully professional communication in a foreign language as they know a uniform vernacular which is formed in the sphere of their educational, and then professional activity.

\section{Conclusions}

A higher education institution as a social institute has to introduce students into the professional world through acquiring ESP. That is an essential element of professional communication and adaptation, and as a result their professional socialization. To meet the demands of the future we need an engineering discourse, which is environmentally aware and socially sensitive and inclusive, while also acknowledging the global nature of engineering. As the above example demonstrates, the situation is slowly starting to change. The main content of the educational program of new generation should be professionally oriented business communication with the dominance on teaching conversational speech. The educational program should include not only authentic textual material that meets the peculiarities of future professional activities of the technical students, but also such activities as role-plays, puzzles and problem-solving exercises that promote meaningful communication, provide fun, develop team-work, foster creative thinking and create opportunities for learners to interact with one another. The given approach will considerably optimize educational process and allow to model real situations of professional interrelation to prepare effective specialists.

\section{REFERENCES}

[1] Pluzhnik, I.L. (2003) The Formation of Cross-Cultural Communicative Competence of the Humanitarian Students in the Process of Professional Training. Tyumen. -29 p.

[2] Arutyunova, N.D. (1990) Discourse /N. D. Arutyunova // the Linguistic encyclopaedic dictionary. - M.: Sov. Encyclop. pp. 136-137.

[3] Karaulov O.I., Petrov V.V. (2015) From the textual grammar to the cognitive discourse theory. Introductory article to the book of Teun A. van Dijk Jazyk, poznanie, kommunikatsia (Language, Cognition and Communication). Moscow:

\section{LENAND, $320 \mathrm{p}$.}

[4] Yeluhina N.V. (2002) The role of discourse in cross-cultural communication and discourse competence formation technique. Inostranniye yasiki v shkole, № 3, p.9-13.

[5] Makarov M.L. (2003) Osnovi teorii discursa (The foundations of discourse theory). Moscow: ITDGK "Gnosis". $-280 \mathrm{pp}$.

[6] Dijk, T. A. van. (1) From text grammar to critical discourse analysis. Academic autobiography. Version 2.0. Unpublished, August 2004.

[7] Dijk, T. A. van. (2) Discourse, context and cognition. Discourse Studies, 8(1), 159-177, 2006.

[8] Dijk, T. A. van. (3) Jazyk, poznanie, kommunikatsia (Language, Cognition and Communication). (Moscow: Progress, 1989) the Linguistic encyclopaedic dictionary. - M.: Sov. Encyclop. p.1324.

[9] Stupnikova, L.V. (2010) Professionally oriented discourse training in jural sphere in the context of cross-cultural relations. Moscow. Moskovskiy gosudarstvenniy lingvisticheskiy iniversitet. - p. 23.

[10] Johnston, S., Lee, A. and McGregor, H. (1996) Engineering as captive discourse. Technè: Research in Philosophy and Technology. Volume 1, Issue 3/4, Spring. - 128-136.

[11] Tenopir C., King D. (2004) Communication Patterns of Engineers. Wiley-IEEE Press. - pp. 149-161.

[12] Sepir, Edward (2002) The chosen works on linguistics and culture science. Moscow.

[13] Vaysburg A.V. (2009) Problems of professional socialization of sociologists in the region. The Regionology Journal, 1, URL: http://regionsar.ru /

[14] Krasnoperova A.G. (2008) Professional and Labour Socialization in the complex of Educational Process. Fundamental researches, 2 (77-79) URL: www.rae.ru/fs/? section $=$ content\&op=show_article\&article_id $=2625$ (date: 02.02.2015)

[15] Sidelnik, E. A. (2010) Language and Professional Socialization of Engineering Students. Izvestiya UFedU, Taganrog. - pp. 123-127.

[16] Shmakova O. V. (2009) Professional socialization of students by means of foreign-language business communication (based on Business English training). Thesis abstract candidate of pedagogic sciences, Novokuznetsk. - $14 \mathrm{p}$.

[17] M.G. Bondarev, A.S. Andrienko, L.V. Burenko, O.G. Melnik, E.A. Sidelnik. (2015) Computer Engineering. Textbook. Moscow. 